\title{
Effects of Various Alkali Metal Cations on the Synthesis, Crystallization and Catalytic Properties of NKX-2 Aluminophosphites
}

\author{
Haruna Abdullahi, ${ }^{a}$ Ka-Lun Wong,,${ }^{\text {,c }}$ Gin Keat Lim, ${ }^{a}$ Hussein Awala, ${ }^{\mathrm{d}}$ Aurélie Vicente, ${ }^{\mathrm{d}}$ Tau \\ Chuan Ling, ${ }^{\text {e }}$ Svetlana Mintova, ${ }^{\mathrm{d}}$ Eng-Poh Ng ${ }^{\mathrm{a}}$ ** \\ ${ }^{a}$ School of Chemical Sciences, Universiti Sains Malaysia, 11800 USM, Penang, Malaysia. \\ ${ }^{b}$ Natural Sciences and Science Education, NIE, Nanyang Technological University, Singapore.
}

'Xiamen University Malaysia, Jalan Sunsuria, Bandar Sunsuria, Sepang, 43900 Sepang, Selangor, Malaysia.

${ }^{d}$ Laboratoire Catalyse \& Spectrochimie, ENSICAEN, Université de Caen, 14000 Caen, France. ${ }^{e}$ Institute of Biological Sciences, Faculty of Science, University of Malaya, 50603 Kuala Lumpur, Malaysia.

*Corresponding author. Tel: +6046533550; e-mail address: epng@usm.my

\begin{abstract}
:
Alkali metal-containing NKX-2 (M-NKX-2) aluminophosphite crystals were hydrothermally synthesized in the $\mathrm{Al}_{2} \mathrm{O}_{3}-\mathrm{P}_{2} \mathrm{O}_{5}-\mathrm{Me}_{2} \mathrm{O}-\mathrm{H}_{2} \mathrm{O}$ system for the first time using various alkali metal hydroxides (MOH: $\mathrm{M}=\mathrm{Li}, \mathrm{Na}, \mathrm{K}, \mathrm{Cs}$ ). The results showed that NKX-2 crystalline phase could be obtained within several hours without using harmful organic amine structure-directing agent. In addition, the alkali metal hydroxides played an important role in controlling the crystallization rate and the morphology of M-NKX-2 particles in aqueous medium. The resulting M-NKX-2 solids possessed basicity which was catalytically active in base-catalyzed cyanoethylation reaction of methanol.
\end{abstract}


Keywords: Alkali metal cation containing NKX-2; Organotemplate-free synthesis; Aluminophosphite; Crystal growth; Cyanoethylation reaction

\section{Introduction}

Zeotype materials with aluminophosphate (AlPO- $n$ ) and silicoaluminophosphate (SAPO- $n$ ) are a class of microporous zeolite analogues widely used in adsorption, separation and catalysis [1-3]. Typically, they are crystallized under hydrothermal conditions with water in a sealed autoclave under autogeneous pressure [4]. The synthesis of AlPO- $n$ materials is also realized by using other methods such as solvothermal synthesis [5], ionothermal approach [6], dry-gel conversion [7], microwave-assisted synthesis [8], etc. [9]. Usually, amines or quaternary ammonium salts are added to direct the formation of a particular porous framework structure [10-12]. So far, there are more than 40 AlPO- $n$ based porous frameworks that have been identified [13].

In general, phosphoric acid $\left(\mathrm{H}_{3} \mathrm{PO}_{4}\right)$ is employed as the phosphorus source. The use of phosphorous acid $\left(\mathrm{H}_{3} \mathrm{PO}_{3}\right)$ as an alternative phosphorus source has recently been reported, offering a new synthesis route of aluminophosphate materials. In this new synthesis process, NKX-2 which is an aluminophosphite, is formed as an important intermediate for synthesizing many useful microporous aluminophosphates (SAPO-46, AlPO-47, AlPO-41, SAPO-31, AlPO-11, AlPO-5 and AlPO-CJ2) [14, 15].

NKX-2 is an aluminophosphite with one-dimensional microporous channels. It was first prepared and reported in 2006 by Li et al. [14]. As like AlPO- $n$ materials, NKX-2 aluminophosphite is formed with the aid of amines or ionic liquids as structural directing agents (SDAs) and $\mathrm{H}_{3} \mathrm{PO}_{3}$ as the phosphorus source $[14,16]$. Recently, we have reported the use of 
$\mathrm{NaOH}$ as an inorganic base to crystallize the NKX-2 particles without the addition of any harmful and expensive organic SDA [17]. The resulting sodium containing NKX-2, surprisingly, possesses basicity and can be used as a solid base catalyst. In addition, a change in the crystallization profiles of NKX-2 is also observed in the SDA-free synthesis system due to the use of alkaline synthesis medium as compared to the weakly alkaline medium (with the presence of amines or ionic liquids) used in previous synthesis systems. It is shown that $\mathrm{Na}^{+}$ ions have significant impact in the formation of NKX-2 crystalline phase, but the chemistry of alkali cations in the formation of NKX-2 is still not clear and hence, it is worth to be further explored.

In this work, NKX-2 aluminophosphite is synthesized in organotemplate-free $\mathrm{Me}_{2} \mathrm{O}-$ $\mathrm{Al}_{2} \mathrm{O}_{3}-\mathrm{P}_{2} \mathrm{O}_{5}-\mathrm{H}_{2} \mathrm{O}$ precursor system using various alkali metal hydroxides $(\mathrm{MOH}=\mathrm{LiOH}$, $\mathrm{NaOH}, \mathrm{KOH}, \mathrm{CsOH}$ ) and $\mathrm{H}_{3} \mathrm{PO}_{3}$ as the mineralizing agents and the phosphorus source, respectively. The crystallization profiles and the morphological properties of the resulting MNKX-2 such as crystallization rate, degree of crystallinity, morphology, crystallite size, elemental composition and crystallography structure are studied by microscopic and spectroscopic methods. Furthermore, the catalytic properties of the materials are also studied in the cyanoethylation reaction of methanol.

\section{Experimental}

\subsection{Chemicals}

$\mathrm{NaOH}(99 \%), \mathrm{KOH}(85 \%)$, ethanol (99.9\%) and acrylonitrile (99\%) were purchased from Merck Chemicals $\mathrm{GmbH}$. $\mathrm{LiOH}$ (98\%) was purchased from Acros Organics while 
$\mathrm{CsOH} \cdot \mathrm{H}_{2} \mathrm{O}(\geq 99.5 \%), \mathrm{H}_{3} \mathrm{PO}_{3}(98 \%)$ and aluminum isopropoxide $(98 \%)$ were purchased from Sigma-Aldrich. All chemicals were used without additional purification.

\subsection{Hydrothermal synthesis of M-NKX-2 crystals $(M=L i, N a, K, C s)$}

For the synthesis of Na-NKX-2, $\mathrm{H}_{3} \mathrm{PO}_{3}(0.744 \mathrm{~g})$, aluminum isopropoxide $(0.416 \mathrm{~g})$ and distilled water (11.713 g) were mixed and stirred in order to obtain a clear solution. $\mathrm{NaOH}$ solution $(1.520 \mathrm{~g}, 5 \mathrm{M})$ was then slowly added into the mixture. A cloudy solution with a molar composition of $1 \mathrm{Al}_{2} \mathrm{O}_{3}: 4.5 \mathrm{P}_{2} \mathrm{O}_{5}: 3.8 \mathrm{Na}_{2} \mathrm{O}: 720 \mathrm{H}_{2} \mathrm{O}$ was obtained after the mixing process. The mixture was then transferred into a $50 \mathrm{~mL}$ Teflon-lined stainless steel autoclave before heating at $180{ }^{\circ} \mathrm{C}$ at various times for crystallization. The autoclave was cooled down to room temperature. The solid product was filtered and washed until $\mathrm{pH} 7$ before drying in an oven at $80{ }^{\circ} \mathrm{C}$ overnight. Similar procedure was used to prepare $\mathrm{Li}-$, $\mathrm{K}$ - and $\mathrm{Cs}-\mathrm{NKX}-2$, except the respective metal hydroxides were used instead of $\mathrm{NaOH}$.

\subsection{Characterization of solids}

The crystallinity and purity of the M-NKX-2 powder samples were studied using a PANalytical X'Pert PRO diffractometer with a $\mathrm{Cu} \mathrm{K \alpha}(\lambda=1.5406 \AA)$ radiation source. The $\mathrm{XRD}$ patterns were obtained in the $2 \theta$ range $5-40^{\circ}$ with a step size of $0.02^{\circ}$ and a scan speed of $0.2^{\circ} / \mathrm{min}$. For identification, the powder XRD patterns were compared with the powder diffraction data (including the $2 \theta$-values for $\mathrm{CuK} \alpha$ radiation, $\mathrm{d}$-spacings and relative intensities) reported in the reference [14]. The degree of crystallinity was determined by evaluating the intensity of the two most intense XRD peaks at $2 \theta$ of $13.05^{\circ}[010], 25.95^{\circ}[111]$ and $29.12^{\circ}$ [021], in comparison to a reference sample (Cs-NKX-2 synthesized for $2 \mathrm{~h}$ ). The crystal 
structure determination was further confirmed by using Rietveld refinement via GSAS software. The morphological characteristics and the average particle size distribution were evaluated by Scanning Electron Microscopy using a FESEM (Leo Supra 50VP) microscope with an accelerating voltage of $20 \mathrm{kV}$. The chemical composition of samples was measured by a Philips PW2404 XRF instrument. The elemental composition mapping of the solid samples was obtained using a FESEM (Leo Supra 50VP) equipped with an Oxford Instruments X-Max 80 $\mathrm{mm}^{2}$ Solid State EDX detector. The infrared (IR) spectra of the solids were recorded with a Perkin Elmer spectrometer (System 2000) within the range of $4000-400 \mathrm{~cm}^{-1}$ using $\mathrm{KBr}$ pellet technique $(\mathrm{KBr}$ : sample weight ratio $=200: 1) .{ }^{27} \mathrm{Al}$ and ${ }^{31} \mathrm{P}$ solid state magic angle spinning (MAS) NMR spectroscopy analyses were performed using a Bruker Ultrashield 500 spectrometer at MAS frequencies between 5 and $15 \mathrm{kHz}$. The ${ }^{27} \mathrm{Al}$ and ${ }^{31} \mathrm{P}$ MAS NMR spectra were recorded with 10000 scans by single-pulse excitation using $\pi / 12(0.6 \mu \mathrm{s})$ and $\pi / 2(3.0 \mu \mathrm{s})$ pulses, respectively. The basicity property of solid sample was determined by using back titration method [18]. Typically, $0.200 \mathrm{~g}$ of dried solid sample was suspended in $10 \mathrm{~mL}$ of distilled water. The solution was magnetically stirred for $24 \mathrm{~h}$ before it was centrifuged (10000 $\mathrm{rpm}, 10 \mathrm{~min}$ ). The separated solution was then mixed with $5 \mathrm{~mL}$ of $0.05 \mathrm{M} \mathrm{HCl}$. The resulting solution was titrated with $0.02 \mathrm{M} \mathrm{NaOH}$ solution while phenolphthalein was used as the indicator. End point was noted when the colorless solution turned to pink. The readings were performed in triplicate for each sample.

\subsection{Catalytic study}

Cyanoethylation reaction of methanol was performed as follows: M-NKX-2 solid ( 0.20 g) was first dehydrated at $100{ }^{\circ} \mathrm{C}$ for $3 \mathrm{~h}$. The catalyst was then loaded into a $15 \mathrm{~mL}$ Teflon lined autoclave containing ethanol (76 mmol, 99\%, Merck) and acrylonitrile (19 mmol, 99\%, 
Merck). The autoclave was capped, sealed and heated at $150{ }^{\circ} \mathrm{C}$ under magnetically stirring (400 rpm). The products were withdrawn after the reaction and analyzed using a GC (HewlettPackard 5880) and GC-MS (Perkin-Elmer GC-IR 2000 system) equipped with a HP-5 capillary column where $n$-nonane was used as an internal standard.

\section{Results and discussion}

\subsection{Synthesis of $M-N K X-2(M=L i, N a, K, C s)$}

The crystallization of M-NKX-2 involves a two-step process, namely nucleation and crystal growth. The sigmoidal crystallization curves extracted from XRD data for Li-, Na-, Kand Cs-NKX-2 are shown in Fig. 1. It can be seen that the induction period of Cs-NKX-2 is much shorter than that of the other three counterparts. For the $\mathrm{P}_{2} \mathrm{O}_{5}-\mathrm{Al}_{2} \mathrm{O}_{3}-\mathrm{Li}_{2} \mathrm{O}-\mathrm{H}_{2} \mathrm{O}$ system, diffraction peaks that indicating crystal formation of Li-NKX-2 is only observed after $6 \mathrm{~h}$ of hydrothermal treatment; fully crystalline sample is obtained when the hydrothermal treatment time reached $8 \mathrm{~h}$. In contrast, when the aluminophosphite is prepared using more alkaline $\mathrm{CsOH}$, highly crystalline Cs-NKX-2 can be produced within $2 \mathrm{~h}$. Hence, the results suggest that the basicity of the alkali hydroxide used does play an important role in accelerating the nucleation stage during the crystallization process $(\mathrm{LiOH}<\mathrm{NaOH}<\mathrm{KOH}<\mathrm{CsOH})$.

The XRD patterns of fully crystalline M-NKX-2 solids are shown in Fig. 2. All samples exhibit XRD peaks at $2 \theta=13.01^{\circ}[010], 25.90^{\circ}[111], 29.10^{\circ}[021], 34.01^{\circ}[112], 34.81^{\circ}$ $[210] /[120]$, which are consistent to those that have been reported in the reference, indicating the formation of pure NKX-2 crystalline phase [14]. In addition, all samples experience different degrees of peak broadening due to the effect of different crystallite size [19]. Thus, the results suggest that Li-NKX-2 aluminophosphite has the smallest crystals as it exhibits the 
broadest XRD peaks. This effect, nevertheless, is becoming less significant for Na-, K- and CsNKX-2. From the XRD analysis, the crystallite size of M-NKX-2 increases following the order $\mathrm{Li}>\mathrm{Na}>\mathrm{K}>\mathrm{Cs}$.

The M-NKX-2 is isostructure to the reported NKX-2 aluminophosphite according to the crystallography study [14] (Fig. 3, Table 1). The structures do not expand significantly on the additional of alkali cations into the NKX-2 structure. Instead, the M-NKX-2 structures are more compact than that of NKX-2 structure, leading to a slight decrease in the structure volume. Previous study has reported that the pure NKX-2 contains a three-linkage $\mathrm{O}$ atom linked by two adjacent $\mathrm{AlO}_{6}$ octahedrals and a distorted $\mathrm{HPO}_{3}{ }^{2-}$ tetrahedral where $\mathrm{Al}-\mathrm{O}-\mathrm{Al}$ linkages, which are forbidden based on the Lowensteins' rule, are formed [20]. In contrast, all four MNKX-2 solids reported in this study follow the Lowenstein distribution. $\mathrm{Six} \mathrm{AlO}_{6}$ octahedrals are linked to six $\mathrm{HPO}_{3}{ }^{2-}$ tetrahedrals to form 1D 12-MR channel system of NKX-2. In addition, the alkali cations are counter-balanced, $(\mathrm{Al}-\mathrm{O}-\mathrm{P}-\mathrm{O})_{2}{ }^{-} \mathrm{M}^{+}$, at the electron-rich 4-numbered ring pockets located near the spacious 12-MR channel along the c-axis (inset of Fig. 3).

Alkali metal cations are also found to have profound effect on the particle morphology. As seen from the SEM micrographs, the use of weak base $\mathrm{LiOH}$ results in the formation of LiNKX-2 crystals with novel acicular (needle-shape) morphology (Fig. 4a). The length of the crystals range from 7.9 to $13.1 \mu \mathrm{m}$ and some of them are intergrown. The core of Li-NKX-2 crystal is revealed in Fig. 4b, showing that the micron-sized Li-NKX-2 crystals are made up of smaller primary crystals with a size of ca. $175 \mathrm{~nm}$. This result is in agreement with the XRD peak broadening observation for this sample. The morphology changes dramatically to bird nest-like shape for Na-NKX-2 (Fig. 4c \& d). As can be seen, the secondary crystal size reduces to ca. $8 \times 3.5 \mu \mathrm{m}^{2}$. Long needle-shaped primary Na-NKX-2 nanocrystals can be observed growing on the surface of the bulk crystals. For K-NKX-2, these primary crystals $(1.3 \times 0.4$ 
$\mu \mathrm{m}^{2}$ ) intergrow and stack in a layer by layer fashion, producing the secondary crystals with grain shape and a size of $9 \times 5.2 \mu \mathrm{m}^{2}$ (Fig. 4e \& f). When the alkali hydroxide is replaced with $\mathrm{CsOH}$, Cs-NKX-2 crystals of grain shape $\left(10.5 \times 6.7 \mu \mathrm{m}^{2}\right)$ are produced (Fig. $\left.4 \mathrm{~g} \& \mathrm{~h}\right)$. The surface of the crystals is smooth and no primary small crystals can be observed, thus agreeing well with the XRD results.

FTIR spectroscopy study has been performed to study the M-NKX-2 porous framework and the effect of the presence of different alkaline cations in the framework (Fig. 5). In general, all four fully crystalline M-NKX-2 samples show almost similar IR pattern as that of pure NKX-2 aluminophosphite [17]. The broad band at $3458 \mathrm{~cm}^{-1}$ is due to the $\mathrm{O}-\mathrm{H}$ stretching from water. The bands at 2481 and $1039 \mathrm{~cm}^{-1}$ are assigned to the $\mathrm{P}-\mathrm{H}$ stretching and deformation modes of $\mathrm{HPO}_{3}{ }^{2-}$, respectively [6]. The IR bands resonate at 1229 and $1139 \mathrm{~cm}^{-1}$ are attributed to the $\mathrm{T}-\mathrm{O}(\mathrm{T}=\mathrm{Al}, \mathrm{P})$ asymmetric stretching vibration [21]. Meanwhile, four characteristic bands at 594, 560, 517 and $445 \mathrm{~cm}^{-1}$, which are due to the T-O-T vibrations, are also detected confirming the formation of the framework structure of NKX-2 [6].

The chemical environment of M-NKX-2 has also been studied using ${ }^{27} \mathrm{Al}$ and ${ }^{31} \mathrm{P}$ MAS NMR spectroscopy. For ${ }^{27}$ Al MAS NMR spectra, two broad bands with a shoulder band are observed for all M-NKX-2 samples (Fig. 6A). These signals can be deconvoluted into three symmetry peaks, located at ca. $8.0 \mathrm{ppm},-7.0 \mathrm{ppm}$ and $-14.8 \mathrm{ppm}$. The first weak peak at ca. $8.0 \mathrm{ppm}$ is assigned to the pentahedral aluminium species due to $\mathrm{Al}(\mathrm{PO})_{4}\left(\mathrm{OH}_{2}\right)$. The second peak resonated at ca. $-7.0 \mathrm{ppm}$ is attributed to the $\left[\mathrm{Al}_{2}\left(\mathrm{HPO}_{3}\right)_{3}\right]$ species, viz. the basic building units of M-NKX-2 crystalline materials. The third peak at ca. $-14.8 \mathrm{ppm}$ is due to the octahedral $\mathrm{AlO}_{6}$ species, which share three $\mathrm{Al}-\mathrm{O}$ corners with three $\mathrm{HPO}_{3}{ }^{2-}$ tetrahedra and three $\mathrm{Al}-\mathrm{O}$ corners with one adjacent $\mathrm{AlO}_{6}$ octahedron [14]. On the other hand, only one nonsymmetry ${ }^{31} \mathrm{P}$ MAS NMR peak is shown by M-NKX-2 (Fig. 6B). This peak can be 
deconvoluted into two peaks. The strong band at ca. $-14.0 \mathrm{ppm}$ is assigned to the $\mathrm{P}(\mathrm{H})(\mathrm{M})\left(\mathrm{OAl} \mathrm{Oct}_{2}\right)_{2}$ tetrahedral species while the peak at ca. $-6.4 \mathrm{ppm}$ corresponds to the lower condensation degree of phosphorus species, which is in agreement with the IR spectroscopy analysis. These results confirm the existence of the $\mathrm{P}-\mathrm{H}$ bond in M-NKX-2 solids [22, 23].

The chemical compositions of the M-NKX-2 samples have been investigated by XRF spectroscopy. No significant difference on the P/Al/M molar ratios are observed when different alkali metal hydroxides are used to prepare M-NKX-2 aluminophosphites (Table 2). The MNKX-2 solids have a P/Al ratio of $\sim 1.55$, which is slightly higher than that of the pure NKX-2 [14]. This suggests that the M-NKX-2 aluminophosphites contain excessive $\mathrm{P}$ sites that contribute to surface negative charge. The created surface charge is then counter-balanced by the extraframework alkali metal cations.

The elemental distribution of M-NKX-2 has been studied by EDX elemental mapping (Fig. 7). As can be seen, $\mathrm{P}, \mathrm{O}$ and $\mathrm{Al}$ elements, which are the basic building elements of NKX2 framework structure, are found in the entire region. In addition, $\mathrm{Na}, \mathrm{K}$ and $\mathrm{Cs}$ elements are also abundant and evenly distributed throughout the samples. No Li element is shown because it has very low energy of characteristic radiation that is not easy to be detected by EDX detector [24].

The XRF and EDX elemental analyses reveal that the M-NKX-2 might have basicity due to the presence of alkali metal extraframework cations. Hence, back titration experiment is used to evaluate the amount of basicity of the samples. The results show that Cs-NKX-2 possesses the highest amount of basicity $\left(310 \mu \mathrm{mol} \mathrm{g} \mathrm{g}^{-1}\right)$, which is nearly 11 times more than Li-NKX-2 $\left(28 \mu \mathrm{mol} \mathrm{g}{ }^{-1}\right)$. On the other hand, K-NKX-2 has $226 \mu \mathrm{mol} \mathrm{g} \mathrm{g}^{-1}$ of basicity which is higher than Na-NKX-2 $\left(193 \mu \mathrm{mol} \mathrm{g}{ }^{-1}\right)$. These titration results hence reveal that M-NKX-2, especially Cs-NKX-2 can be a potential solid base catalyst. 


\subsection{Catalytic behaviour of $M-N K X-2$}

The catalytic behaviour of M-NKX-2 (M = Li, Na, K, Cs $)$ has been tested on cyanoethylation reaction of methanol, under autogeneous condition and free of organic solvent. No conversion is observed when the reaction is conducted in the absence of M-NKX-2 catalyst. Hence, this indicates that cyanoethylation of methanol is an activated catalytic reaction. The catalytic study shows that the cyanoethylation reaction is more favorable when Cs-NKX-2 is used as a catalyst (Fig. 8). The conversion reaches $89.94 \%$ after $14 \mathrm{~h}$ of reaction with $100 \%$ selectivity to 3-ethoxy-propionitrile. The catalytic reactivity, however, decreases orderly when the catalyst is replaced with K-, Na- and Li-NKX-2. Only $69.22 \%, 58.86 \%$ and $13.97 \%$ of conversion are measured when K-, Na- and Li-NKX-2 are used, respectively. The results reveal that the catalytic performance follow the basicity of the cations present in the M-NKX-2: $\mathrm{Cs}^{+}>$ $\mathrm{K}^{+}>\mathrm{Na}^{+}>\mathrm{Li}^{+}$

Catalyst reusability is a major problem for solid catalysts in liquid phase reaction [25]. Therefore, Cs-NKX-2 has been chosen for the catalytic reusability test. The results show that Cs-NKX-2 is recyclable since the reactivity of the recovered solid can be preserved at least up to six consecutive runs (conversion ca. $86.57 \%$ and selectivity to 3-ethoxy-propionitrile remains 100\%) (Fig. 9). A slight decrease in the catalytic conversion is observed after each cycle of reaction which can be due to the physical loss of Cs-NKX-2 during catalyst recovery by centrifugation. The results also suggest that the extraframework $\mathrm{Cs}^{+}$alkali cations are strongly bounded to the NKX-2 surface via electrostatic attraction force, and hence it remains catalytically active to the cyanoethylation reaction even after several reaction runs.

\section{Conclusions}


In conclusion, $\mathrm{M}-\mathrm{NKX}-2$ containing various inorganic cations $(\mathrm{M}=\mathrm{Li}, \mathrm{Na}, \mathrm{K}$ and $\mathrm{Cs})$ have been successfully synthesized from organotemplate-free hydrogel systems. Compared to pure NKX-2, the M-NKX-2 can be crystallized within several hours without using aminic organic template. Furthermore, the crystallization kinetics of M-NKX-2 is found to be significantly affected by the type of metal hydroxide used; $\mathrm{CsOH}$ crystallizes Cs-NKX-2 within $2 \mathrm{~h}$ whereas $\mathrm{LiOH}$ produces fully crystalline Li-NKX-2 after $8 \mathrm{~h}$. The morphology and the crystallite size of M-NKX-2 crystals are also affected by the alkali metal hydroxides used. MNKX-2 solids, particularly Cs-NKX-2, are catalytically active in base-catalyzed cyanoethylation reaction of methanol. The results reveal that Cs-NKX-2 gives the highest conversion among the four solids prepared with $100 \%$ selectivity to 3 -ethoxy-propionitrile. The Cs-NKX-2 catalyst can be a promising base catalyst in cyanoethylation reaction under autogenic pressure since the solid can be easily separated from the reaction media. The solid catalyst is recyclable with small loss of activity up to six cycles.

\section{Acknowledgement}

The financial support from FRGS (203/PKIMIA/6711495, 203/PKIMIA/6711461) and RUI (1001/PKIMIA/8011012) grants is gratefully acknowledged. H. Abdullahi also thanks Tertiary Education Trust Fund (TETFund) for a doctoral scholarship.

\section{References}

[1] N.N.R. Ahmad, C.P. Leo, A.W. Mohammad, A.L. Ahmad, Modification of gas selective SAPO zeolites using imidazolium ionic liquid to develop polysulfone mixed matrix membrane for CO2 gas separation, Micropor. Mesopor. Mater. 244 (2017) 21-30. 
[2] J. Wang, M. Yang, W. Shang, X. Su, Q. Hao, H. Chen, X. Ma, Synthesis, characterization, and catalytic application of hierarchical SAPO-34 zeolite with threedimensionally ordered mesoporous-imprinted structure, Micropor. Mesopor. Mater. $252(2017) 10-16$.

[3] L. Tosheva, E.-P. Ng, S. Mintova, M. Hölzl, T.H. Metzger, A.M. Doyle, AlPO4-18 Seed Layers and Films by Secondary Growth, Chem. Mater. 20 (2008) 5721-5726.

[4] D.Y. Khoo, W.M. Kok, R.R. Mukti, S. Mintova, E.-P. Ng, Ionothermal approach for synthesizing AlPO-5 with hexagonal thin-plate morphology influenced by various parameters at ambient pressure, Solid State Sci. 25 (2013) 63-69.

[5] X. Jiao, D. Chen, W. Pang, Y. Yue, Solvothermal synthesis and characterization of TiAPO-41, Mater. Lett. 51 (2001) 236-239.

[6] M.M. Azim, A. Pensado, B. Kirchner, T. Gutmann, P.B. Groszewicz, G. Buntkowsky, A. Stark, Ionothermal synthesis of crystalline microporous aluminophosphates: Systematic study on the conditions affecting the framework type, Micropor. Mesopor. Mater. 266 (2018) 204-213.

[7] S. Tao, X. Li, H. Gong, Q. Jiang, W. Yu, H. Ma, R. Xu, Z. Tian, Confined-space synthesis of hierarchical MgAPO-11 molecular sieves with good hydroisomerization performance, Micropor. Mesopor. Mater. 262 (2018) 182-190.

[8] E.-P. Ng, D.T.-L. Ng, H. Awala, K.-L. Wong, S. Mintova, Microwave synthesis of colloidal stable AlPO-5 nanocrystals with high water adsorption capacity and unique morphology, Mater. Lett. 132 (2014) 126-129. 
[9] X. Zhao, X. Gao, X. Zhang, Z. Hao, Solventless synthesis of AEL-type aluminophosphate molecular sieve from mechanochemically pretreated low-templated reactants, Micropor. Mesopor. Mater. 242 (2017) 160-165.

[10] J. Wang, M. Yang, J. Zhang, S. Zhang, X. Wang, K. Fu, M. Wang, W. Shang, H. Chen, X. Ma, Fabrication of BEA/MFI zeolite nanocomposites by confined space synthesis, Mater. Chem. Phys. 207 (2018) 167-174

[11] Y. Chen, C. Li, X. Chen, Y. Liu, C. Liang, Synthesis of ZSM-23 zeolite with dual structure directing agents for hydroisomerization of n-hexadecane, Micropor. Mesopor. Mater. 268 (2018) 216-224.

[12] C. Wang, S. Feng, L. Liu, Q. He, J. Dong, A facile route to encapsulate ultrasmall Ni clusters within the pore channels of AlPO-5, Mater. Lett. 210 (2018) 211-213.

[13] IZA-SC Database of zeolite structures. http://www.iza-structure.org/databases/.

[14] N. Li, Y. Ma, S. Xiang, N. Guan, Capturing an Aluminophosphite Intermediate in the New Route of Synthesizing Zeolite-like Aluminophosphates, Chem. Mater. 18 (2006) 975-980.

[15] N. Li, G. Cao, S. Xiang, Synthesizing large single crystals of aluminophosphate molecular sieves from a novel route, Stud. Surf. Sci. Catal. 154A (2004) 1001-1006.

[16] Y. Shi, X. Zhang, L. Wang, G. Liu, Ionothermal synthesis of aluminophosphite NKX2, Mater. Lett. 124 (2014) 212-214.

[17] L. Gopal, G.K. Lim, T.C. Ling, R. Adnan, J.C. Juan, E.-P. Ng, Organotemplate-free hydrothermal synthesis of NaNKX-2 aluminophosphite base catalyst, Mater. Lett. 182 (2016) 344-346. 
[18] M.F. Othman, S.S. Lapari, Z. Ramli, S. Triwahyono, Synthesis of mesoporous sodalite by mixed quaternary ammonium cation templates for knoevenagel condensation reaction, Malay. J. Anal. Sci. 21 (2017) 860-870.

[19] A. W. Burton, Powder diffraction in zeolite science - an introductory guide, in: A. W. Chester, E. G. Derouane (Eds.), Zeolite Characterization and Catalysis; a Tutorial, Springer, Dordrecht, 2009, pp. 1-64.

[20] G. Busca, Acidity and basicity of zeolites: A fundamental approach, Micropor. Mesopor. Mater. 254 (2017) 3-16.

[21] E.-P. Ng, G.K. Lim, G.-L. Khoo, K.-H. Tan, B.S. Ooi, F. Adam, T.C. Ling, K.-L. Wong, Synthesis of colloidal stable Linde Type J (LTJ) zeolite nanocrystals from rice husk silica and their catalytic performance in Knoevenagel reaction, Mater. Chem. Phys. 155 (2015) 30-35.

[22] A. Sayari, I. Moudrakovski, J.S. Reddy, C.I. Ratcliffe, J.A. Ripmeester, K.F. Preston, Synthesis of Mesostructured Lamellar Aluminophosphates Using Supramolecular Templates, Chem. Mater. 8 (1996) 2080-2088.

[23] Z. Luan, D. Zhao, H. He, J. Klinowski, L. Kevan, Characterization of Aluminophosphate-Based Tubular Mesoporous Molecular Sieves, J. Phys. Chem. B 102 (1998) 1250-1259.

[24] S. Muto, K. Tatsumi, Detection of local chemical states of lithium and their spatial mapping by scanning transmission electron microscopy, electron energy-loss spectroscopy and hyperspectral image analysis, Microscopy 66 (2017) 39-49. 
[25] E.G. Vieira, R.O. Silva, D.R. do Carmo, E.F. Junior, N.L.D. Filho, Synthesis and comparison of the activities of a catalyst supported on two silicate materials, Mater. Chem. Phys. 191 (2017) 197-205.

\section{Graphical abstract}

\section{Effects of Various Alkali Metal Cations on the Synthesis, Crystallization and Catalytic Properties of NKX-2 Aluminophosphites}

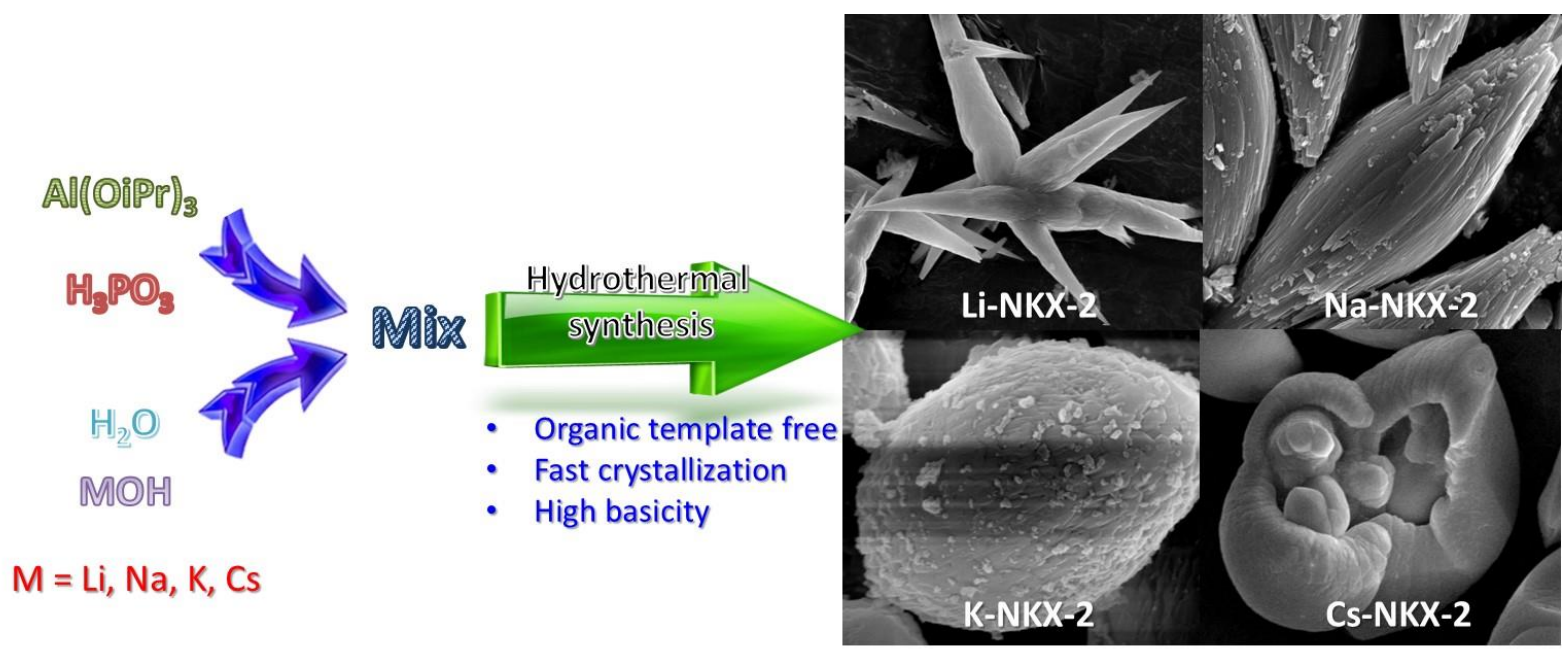

\section{Research Highlights}

- Alkali metal containing NKX-2 is synthesized in $\mathrm{Al}_{2} \mathrm{O}_{3}-\mathrm{P}_{2} \mathrm{O}_{5}-\mathrm{Na}_{2} \mathrm{O}-\mathrm{H}_{2} \mathrm{O}$ system.

- The use of different metal hydroxides significantly alters the crystallization time.

- The morphological and crystallographic properties are also changed.

- The solids exhibit basic character and are active in cyanoethylation of methanol. 


\section{Tables}

Table 1: Crystal data of pure NKX-2 and M-NKX-2 from Rietveld refinement.

\begin{tabular}{cccccc}
\hline & NKX-2 & Li-NKX-2 & Na-NKX-2 & K-NKX-2 & Cs-NKX-2 \\
\hline Space group & $\mathrm{P} 6_{3} / \mathrm{m}$ & $\mathrm{P}_{3} / \mathrm{m}$ & $\mathrm{P} 63 / \mathrm{m}$ & $\mathrm{P} 6_{3} / \mathrm{m}$ & $\mathrm{P6} / \mathrm{m}$ \\
$\mathrm{a}(\AA)$ & $7.8762(11)$ & $7.8549(7)$ & $7.8755(5)$ & $7.8766(5)$ & $7.86290(7)$ \\
$\mathrm{b}(\AA)$ & 7.8762 & 7.8549 & 7.8755 & 7.8766 & 7.8629 \\
$\mathrm{c}(\AA)$ & $7.1237(14)$ & $7.0936(7)$ & $7.0994(5)$ & $7.1005(4)$ & $7.09166(7)$ \\
$\alpha\left({ }^{\circ}\right)$ & 90 & 90 & 90 & 90 & 90 \\
$\beta\left({ }^{\circ}\right)$ & 90 & 90 & 90 & 90 & 90 \\
$\gamma\left({ }^{\circ}\right)$ & 120 & 120 & 120 & 120 & 120 \\
${\text { Volume }\left(\AA^{3}\right)}^{3}$ & 382.71 & 379.034 & 381.337 & 381.502 & 379.703 \\
\hline Data from Ref. $[14]$ & & & & & \\
\hline
\end{tabular}

a Data from Ref. [14]. 
Table 2. Properties of M-NKX-2 solid products.

\begin{tabular}{|c|c|c|c|c|c|c|}
\hline \multirow[b]{2}{*}{ Samples } & \multicolumn{4}{|c|}{ XRF spectroscopy analysis ${ }^{a}$} & \multirow{2}{*}{$\begin{array}{l}\mathrm{P} / \mathrm{Al} / \mathrm{M} \text { molar } \\
\text { ratio }\end{array}$} & \multirow{2}{*}{$\begin{array}{l}\text { P/Al molar } \\
\quad \text { ratio }\end{array}$} \\
\hline & $\mathrm{P}_{2} \mathrm{O}_{5}(\%)$ & $\mathrm{Al}_{2} \mathrm{O}_{3}(\%)$ & $\mathrm{M}_{2} \mathrm{O}(\%)$ & $\begin{array}{c}\text { Others } \\
(\%)\end{array}$ & & \\
\hline Li-NKX-2 & 66.11 & 30.48 & 3.33 & 0.08 & $0.93 / 0.60 / 0.22$ & 1.56 \\
\hline Na-NKX-2 & 63.30 & 29.49 & 7.06 & 0.15 & $0.89 / 0.58 / 0.23$ & 1.54 \\
\hline K-NKX-2 & 60.52 & 28.46 & 10.88 & 0.14 & $0.85 / 0.56 / 0.23$ & 1.53 \\
\hline Cs-NKX-2 & 50.90 & 23.60 & 25.38 & 0.12 & $0.72 / 0.46 / 0.18$ & 1.55 \\
\hline
\end{tabular}

an mass $\%$ 